\title{
Lambdoid synostosis and occipital plagiocephaly: clinical decision rules for surgical intervention
}

\author{
Benjamin S. Carson, M.D., Carol S. James, P.A.C., Craig A. VanderKolk, M.D., and Michael \\ Guarnieri, Ph.D.
}

Departments of Neurosurgery and Plastic Surgery, Johns Hopkins Medical Institutions, Baltimore, Maryland

Lambdoid craniosynostosis has been regarded as one of the least common categories of premature fusion of the cranial sutures, yet reports have suggested the incidence may be increasing. To guide treatment decisions, the authors describe a set of rules based on radiographic indicators and clinical assessment in the child. Experience suggests that children can have abnormal-appearing cranial sutures with normal neurological status and normal-appearing sutures with neurological deficits or marked cerebral compression. Early evaluation and follow-up treatment is essential for children with suspected craniosynostosis.

Key Words * craniosynostosis * lambdoid synostosis * occipital plagiocephaly * pediatric craniofacial surgery * clinical decision rules * pediatric neurosurgery * children

A wide range of poorly characterized genetic, nutritional, toxicological, and mechanical influences may cause occipital skull deformities in the neonatal skull. These deformities are often associated with increased intracranial pressure (ICP) and visual impairment.[11,12,17,18,61,73] Data on the incidence of such impairments are uncertain and difficult to assemble because cranial deformities are not often lethal, not always recognized at birth, and not recorded in adults.[10] Studies have indicated a baseline of 0.2 to 0.5 cases of craniosynostosis per 1000 births. $[10,15]$ A subset of the craniosynostoses, unilambdoid synostosis, accounted for approximately $1 \%$ of cases in three series, $[14,43,62]$ zero cases in a review of 204 patients,[2] and four cases (3\%) in a series of 130 patients with craniosynostosis.[30] Other reports suggest that lambdoid deformities may have been underdiagnosed in earlier series.[20,25,47,49]

Since the early 1990s, referral centers have noted remarkable increases in posterior plagiocephaly. In 1996, for example, our Cranial Facial Clinic received 10-fold more referrals for occipital plagiocephaly (210 infants) compared with 1991. Similar increases have been reported at other tertiary centers.[3,20,25,29,30,34,36,47,69,70]

Increased awareness of the condition and improved diagnostic imaging technology have undoubtedly contributed to the increase. Epidemiological studies indicate that environmental factors including maternal smoking play a role.[1,7,64] Maternal or paternal age effects have not been implicated.[37] Several lines of evidence indicate that the increase almost entirely relates to the recommendation formalized in 1992 by the American Academy of Pediatrics. The recommendation states that infants 
should be placed to sleep in supine or side positioning to reduce the risk of sudden infant death syndrome. Plagiocephaly is generally noted between 3 and 6 months of age; there is little radiographic evidence for increased lambdoid craniosynostosis and the deformity seems to be treatable with positional molding devices, soft-shell helmets, and frequent head turning.[3,34,69]

Several groups have stated that surgical intervention is rarely needed to treat occipital plagiocephaly and never indicated in the absence of radiographic evidence of craniosynostosis.[3,30,31,34,69] We agree that surgical intervention is rarely indicated; however, we believe that clinical decision-making rules based on radiographic detection of fusion of the lambdoid sutures may be difficult to evaluate because premature fusion may be difficult to detect. Moreover, our experience suggests that children can have abnormal-appearing sutures with normal neurological status and normal-appearing sutures with neurological deficits or marked cerebral compression.

To guide treatment decisions and to quantitate the results, we describe a new set of rules based on radiographic indicators of the brain rather than the bone and clinical assessment of the child. These rules are simple to apply and they offer a powerful tool for the crucial early evaluation and follow-up treatment of children with suspected craniosynostosis. A preliminary oral report of this work has been given (Carson, et al., unpublished data).

\section{CLINICAL PRESENTATION}

Pediatricians most often request neurosurgical and plastic surgery consultation for an infant with abnormal head circumference in relation to standard growth curves, but who appears otherwise normal in growth and development. Infants are also referred for posterior and several other cranial deformities that are considered to be caused by positional molding. The anomaly is frequently noted at birth; the parents report a progressive worsening of the deformity and routinely express a concern about potential developmental abnormalities. The infant is usually brought to medical attention by the age of 6 months.[71]

Anatomically, the occipital region appears flattened with anterior compensatory changes and asymmetry in the ear position. Contralateral anterior flattening and unilateral anterior bossing are generally mild. Cases of unilateral craniosynostosis have compensatory growth in the contralateral parietooccipital region that are manifested by bossing and vertex elongation. This elongation is more prominent in bilateral deformities, which also have lateral parietal widening, occipital flattening with anterior narrowing, and increased frontal projection.[34,69]

The asymmetry of the ears reflects the abnormality in the growth of the cranial base and may indicate suture growth disturbance. The ears are displaced anteriorly in bilateral deformities. In right-sided deformities, the ears commonly rotate counterclockwise, leaving the right ear more anterior in relation to the left.[71] Skull base deformities can worsen to the point of affecting oral occlusion.[25,33]

Differential diagnoses include torticollis, positional molding, and craniosynostosis (both actual and functional). Functional craniosynostosis manifests the same clinical symptoms as actual craniosynostosis, but the sutures appear open on plain x-ray films and computerized tomography (CT) scans in the functional case. Torticollis involves a shortened sternocleidomastoid muscle, which can result in flattening of the temporal and occipital region. The anterior deformity typically is greater than the posterior deformity and is found on the side of the abnormality. This usually mild deformity improves with neck exercises and physical therapy. The muscle rarely needs to be divided or lengthened. 
Positional molding anomalies are usually mild and noticed at birth or soon thereafter. The infant may sleep on its back and have slight flattening of the occipital region. These problems generally correct themselves as the infant grows and begins to roll over, although sometimes assistive devices are useful. Huang and coworkers[30] compared the compensatory contralateral parietal and frontal bossing and ipsilateral occipitomastoid bulge in four patients with unilambdoid synostosis to 98 patients with positional molding. The skull base in the former group had an ipsilateral inferior tilt, with corresponding inferior and posterior displacement of the ipsilateral ear, "characteristics completely opposite to the findings in the patients who had positional molding with open lambdoid sutures."[30]

\section{RADIOGRAPHIC INDICATORS}

Three-dimensional CT is obtained to evaluate the infant's skull, cranial base, and brain. The initial CT is used to evaluate the amount of asymmetry of the skull and the compensatory changes that have occurred.[14,40] An open anterior fontanelle and sutures are frequently demonstrated. Fernback and Feinstein[20] have reported that a deformed petrous bone, demonstrated on plain X-ray films, may be an indicator of premature lambdoid synostosis. There is usually sclerosis of the inferior inner aspect of the suture, which is evident on axial CT scans in this region. In seven of 10 patients evaluated, the shape of the suture was end-to-end rather than overlapping, as seen on the normal contralateral side.[70]

Computerized tomography scanning in occipital deformities may also reveal abnormalities of the brain and the bone. Infants with severe deformities typically show diminished posterior subarachnoid fluid similar to the changes seen with increased ICP but on a more localized basis. This appears to extend into the ventricular system resulting in ventricular effacement. Generalized subarachnoid space dilation per se does not indicate neurological impairment because it is frequently found in occipital plagiocephaly with normal neurological status.[59] With severe compression, sometimes the ipsilateral perimesencephalic cistern is also effaced. This finding usually correlates with an irregular, patchy diminished thickness of the occipital bone. The patchiness is greatest in cases of bilateral deformity and appears to be similar to the copper-beaten or thumb-printing appearance seen on plain radiographs. These findings support the theory espoused by Kaiser[32] that bilateral deformities involve increased ICP that requires surgical intervention, although "copper beating" itself may not be a good marker for raised ICP because it occurs late and is an inconsistent finding.[21,68]

\section{DECISION-MAKING RULES}

We report a simple system to guide decision-making for surgical correction of occipital plagiocephaly. The grading system depends on three radiographic descriptors: 1) scalloping of the inner table of the skull; 2) subarachnoid space shifting; and 3) ventricular effacement, as well as a clinical assessment of the child's general physical and neurological status, as shown in Table 1. The system gives pediatric health care providers guidelines to help determine the necessity of neurosurgical referral and possible intervention. It also serves as a basis for epidemiological studies of craniofacial abnormalities. 


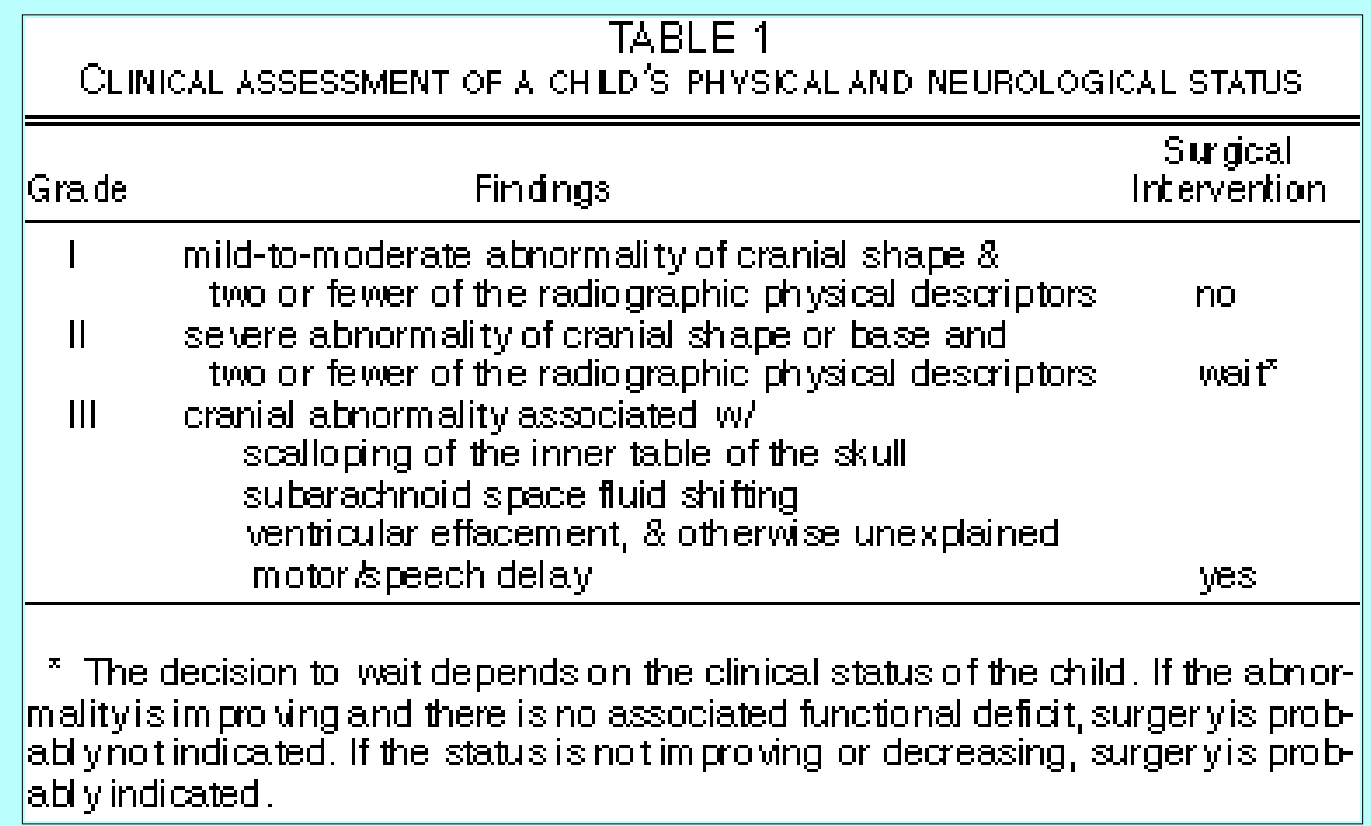

We believe that the majority of infants presenting with mild or moderate asymmetry will not require corrective surgery. This assumption, however, has been difficult to test without a quantitative grading system. Mild asymmetries per se appear to be of little threat to normal intelligence. Recent reports have indicated that mental development in infants with nonsyndromic, single suture craniosynostosis appears to be normal in the absence of increased ICP and other pathologies.[4,35] In this regard, it is of interest to note the recent anthropological studies of the many civilizations that practiced the creation of cranial deformation for cosmetic and political gains.[22,23] Such practices imply that an abnormal skull shape does not interfere with normal intelligence, although one cannot conclude that the physiological results of endogenous and exogenous deformations are the same.

Our system depends only on radiographic indicators and clinical observations. Previous studies have confirmed craniosynostosis by histological studies. Histological samples can be misleading because craniosynostosis usually begins at a single point and spreads along the suture.[12,28] Similarly, the lack of a closed suture on CT does not imply a normal suture or normal function. Fusion at a localized position can have a deleterious effect on the function of the suture, cranial bones, and general cranial growth. Morphological diagnosis by radiography appears to be remarkably accurate (reviewed by Fernbach and Feinstein[20]). Suture abnormalities do not appear to exist as a continuum with normal development and reports of uncertainties in the diagnosis may be attributed to inexperienced readers and ambiguous imaging rather than genuine similarities between abnormal and normal states.[53]

The molecular defects and pathophysiology of craniosynostosis are coming under increasing scrutiny with the identification of relevant genes and gene products.[26,41,48,50] Recent hypotheses suggest that craniosynostosis results when bone scaffolding processes occur prematurely[8] or from increased osteoblastic cell maturation.[16] In lambdoid craniosynostosis, anomalies in skull morphology usually precede complications such as visual impairment and increased ICP.[17,73] Hydrocephalus frequently occurs with syndromic synostosis, and is rarely found in simple, nonsyndromic craniosynostosis;[24] however, increased ICP is not rare. Thompson and coworkers[66] found elevated ICP in 13 of 74 children evaluated for premature closure of a single cranial suture.

Elevated ICP appears to be the driving force behind neurological deficits. Intracranial pressure may not be readily apparent on imaging studies or from clinical signs or symptoms.[9,58,67,76] Several groups 
have reported the persistence of elevated ICP after cranial vault decompression; thus, the simple concept of restricted skull volume does not appear to explain sufficiently all cases of raised ICP.[9,21,44,55,65]

\section{SURGICAL INTERVENTION}

Surgical advances have addressed the question of technique through a union of multidisciplinary pediatric neurosurgical and plastic surgery teams to achieve optimum cranioorbital recontouring and cosmetic results.[13,18,52,72] Still, accurate methods to document the presenting deformity and postoperative results are limited; thus, guidelines for the evaluation of the results are few.[54,56]

Because abnormality at a single suture strongly influences the development of other areas in the craniofacial complex, there is a clinical impression that surgical correction during the neonatal period yields superior results.[6,25,42,43,45,49,51,60,61,72] Wall and colleagues[75] recommend that in the absence of clinical or radiological signs of raised ICP, surgery should be delayed until the patient reaches 12 to 15 months of age.

Protocols for surgical management have been described.[27,34,39,46,66] Whenever there is a question of nonintervention, it is essential to monitor the case closely because apparently well-tolerated cranial deformities can abruptly worsen either spontaneously or following head injury.[17,27,73]

\section{DISCUSSION}

When occipital plagiocephaly is severe enough to produce marked cerebral compression as demonstrated by clinical signs and the radiographic descriptors listed in the Decision-Making Rules section, and the condition is progressive or nonrelenting, it is unwise to base all decisions on whether lambdoid sutures appear to be fused. The brain is more important than the bone that contains it. In cases of occipital plagiocephaly or clear lambdoid craniosynostosis with only mild cerebral compression, our system would not advocate surgical correction, whereas in other cases, in which the sutural abnormality is less clear, but the brain is severely compressed, our system would advocate surgical correction after failure of conservative management. We have not emphasized studies that demonstrate metabolic and blood flow abnormalities in cases of craniosynostosis or cerebral compression because the implications of these abnormalities are still to be defined. It should be emphasized that the majority of patients with posterior plagiocephaly can be managed with assistive devices that prevent the infant from sleeping on the flattened side. In most patients who are unresponsive, surgery should be considered.

It is important to recognize that our system cannot be viewed as an absolute. For example, the decision not to operate can change with new information. Approximately $1 \%$ of the patients with single suture synostosis progress to involve multiple sutures.[57] Surgery itself may have to be repeated; it is not uncommon for patients to develop increased ICP after initial suture release and decompression.[12,63,65] It also should be noted that not all lambdoid deformities are the result of craniosynostosis.[5,74] Finally, severe cosmetic factors are in their own right a valid indication for surgery, especially as the intraoperative risks become lower with improved techniques.[19,38]

\section{References}

1. Alderman BW, Zamudio S, Baron AE, et al: Increased risk of craniosynostosis with higher antenatal maternal altitude. Int J Epidemiol 24:420-426, 1995

2. Anderson FM, Geiger L: Craniosynostosis. A survey of 204 cases. J Neurosurg 22:229-240, 1965 
3. Argenta LC, David LR, Wilson JA, et al: An increase in infant cranial deformity with supine sleeping position. J Craniofac Surg 7:5-11, 1996

4. Arnaud E, Renier D, Marchac D: Prognosis for mental function in scaphocephaly. J Neurosurg 83:476-479, 1995

5. Becker LE, Hinton DR: Pathogenesis of craniosynostosis. Pediatr Neurosurg 22:104-107, 1995

6. Bhardwaj M, Rohtagi M: Post-operative mental development in patients with hydrocephalus and craniosynostosis. Ind Pediatr 31:1301-1304, 1994

7. Bradley CM, Alderman BW, Williams MA, et al: Parental occupations as risk factors for craniosynostosis in offspring. Epidemiology 6:306-310, 1995

8. Burke MJ, Winston KR, Williams S: Normal sutural fusion and the etiology of single sutural craniosynostosis: the microspicule hypothesis. Pediatr Neurosurg 22:241-247, 1995

9. Campbell JW, Albright AL, Losken HW, et al: Intracranial hypertension after cranial vault decompression for craniosynostosis. Pediatr Neurosurg 22:270-273, 1995

10. Cohen MM: Craniosynostosis Diagnosis, Evaluation, and Management. New York: Raven Press, 1986, pp 1-606

11. Cohen MM Jr: Sutural biology and the correlates of craniosynostosis. Am J Med Genet 47:581-616, 1993

12. Cohen SR, Dauser RC, Newman MH, et al: Surgical techniques of cranial vault expansion for increases in intracranial pressure in older children. J Craniofac Surg 4:167-176, 1993

13. Czorny A, Yettou H, Forlodou P, et al: [The posterior part of the skull. Classification of dysmorphism. Original treatment: turned biparietal flap transposition.] Neurochirurgie 41:295-314, $1995(\mathrm{Fr})$

14. Darling CF, Byrd SE, Allen ED, et al: Three-dimensional computed tomography imaging in the evaluation of craniofacial abnormalities. J Natl Med Assoc 86:676-680, 1994

15. David JD, Poswillo D, Simpson D: The Craniosynostoses: Causes, Natural History, and Management. Berlin: Springer-Verlag, 1982, pp 1-331

16. DePollack C, Renier D, Hott M, et al: Increased bone formation and osteoblastic cell phenotype in premature cranial suture ossification (craniosynostosis). J Bone Min Res 11:401-407, 1996

17. DiRocco C, Iannelli A, Velardi F: Early diagnosis and surgical indication in craniosynostosis. Childs Brain 6:175-188, 1980

18. Dufresne CR, Carson BS, Zinreich SJ: Complex Craniofacial Problems: A Guide to Analysis and Treatment. New York: Churchill Livingstone, 1992

19. Fehlow P: Craniosynostosis as a risk factor. Childs Nerv Syst 9:325-327, 1993

20. Fernbach SK, Feinstein KA: The deformed petrous bone: a new plain film sign of premature lambdoid synostosis. AJR 156:1215-1217, 1991 
21. Gault DT, Renier D, Marchac D, et al: Intracranial pressure and intracranial volume in children with craniosynostosis. Plas Reconstr Surg 90:377-381, 1992

22. Gerszten PC, Gerszten E: Intentional cranial deformation: a disappearing form of self-mutilation. Neurosurgery 37:374-382, 1995

23. Gerszten PC, Martínez AJ: The neuropathology of South American mummies. Neurosurgery 36:756-761, 1995

24. Golabi M, Edwards MSB, Ousterhout DK: Craniosynostosis and hydrocephalus. Neurosurgery 21:63-67, 1987

25. Goodrich JT, Hall CD, Argamaso R: The diagnosis and surgical management of lambdoidal synostosis, in Goodrich JT, Hall CD (eds): Craniofacial Anomalies: Growth and Development From a Surgical Perspective. New York: Thieme, 1995, pp 33-42

26. Gorry MC, Preston RA, White GJ, et al: Crouzon syndrome: mutations in two spliceoforms of FGFR2 and a common point mutation shared with Jackson-Weiss syndrome. Hum Molec Genet 4:1387-1390, 1995

27. Gosain AK, McCarthy JG, Wisoff JH: Morbidity associated with increased intracranial pressure in Apert and Pfeiffer syndromes: the need for long-term evaluation. Plast Reconstr Surg 97:292-301, 1996

28. Hinton DR, Becker LE, Muakkassa KF, et al: Lambdoid synostosis. Part 1: The lambdoid suture: normal development and pathology of synostosis. J Neurosurg 61:333-339, 1984

29. Hockley AD: Craniosynostosis. Lancet 342:189-190, 1993

30. Huang MHS, Gruss JS, Clarren SK, et al: The differential diagnosis of posterior plagiocephaly: true lambdoid synostosis versus positional molding. Plast Reconstr Surg 98:765-774, 1996

31. Hunt CE, Puczynski MS: Does supine sleeping cause asymmetric heads? Pediatrics 98:127-129, 1996

32. Kaiser G: The clinical significance of bilateral synostosis of the lambdoid suture and the usefulness of its treatment. Childs Brain 11:87-98, 1984

33. Kane AA, Lo LJ, Vannier MW, et al: Mandibular dysmorphology in unicoronal synostosis and plagiocephaly without synostosis. Cleft Pal Craniofac J 33:418-423, 1996

34. Kane AA, Mitchell LE, Craven KP, et al: Observations on a recent increase in plagiocephaly without synostosis. Pediatrics 97:877-885, 1996

35. Kapp-Simon KA: Mental development in infants with nonsyndromic craniosynostosis with and without cranial release and reconstruction. Plast Reconstr Surg 94:408-410, 1994 (Letter)

36. Kirby PJ, Beverley DW, Batchelor AG: Frequency of craniosynostosis in Yorkshire, UK. Lancet 341:1412-1413, 1993 (Letter)

37. Lajeunie E, Le Merrer M, Bonaiti-Pellie C, et al: Genetic study of scaphocephaly. Am J Med Genet 62:282-285, 1996 
38. Langman MW: Psychological aspects of cranial deformities in patients with craniosynostosis, in Persing JA, Edgerton MT, Jane JA (eds): Scientific Foundations and Surgical Treatment of Craniosynostosis. Baltimore: Williams \& Wilkins, 1989, pp 275-279

39. Lauritzen C: The Goteborg protocol for treatment of craniosynostosis. Scand J Plast Reconstr Surg Hand Surg Suppl 27:11-17, 1995

40. Leboucq N, Montoya P, Martinez Y, et al: Lambdoid craniosynostosis. A 3D-computerized tomographic approach. J Neuroradiol 20:24-33, 1993

41. Ma HW, Lajeunie E, Le Merrer M, et al: No evidence of genetic heterogeneity in Crouzon craniofacial dysostosis. Hum Genet 96:731-735, 1995

42. Marchac D, Renier D, Arnaud E: Evaluation of the effect of early mobilization of the supraorbital bar on the frontal sinus and frontal growth. Plast Reconstr Surg 95:802-811, 1995

43. Marchac D, Renier D, Broumand S: Timing of treatment for craniosynostosis and facio-craniosynostosis: a 20-year experience. Br J Plast Surg 47:211-222, 1994

44. Marsh JL: Discussion of Posnick JC, Armstrong D, Bite U: Metopic and sagittal synostosis: intracranial volume measurements prior to and after cranio-orbital reshaping in childhood. Plast Reconstr Surg 96:310-315, 1995

45. McCarthy JG, Glasberg SB, Cutting CB, et al: Twenty-year experience with early surgery for craniosynostosis: I. Isolated craniofacial synostosis--results and unsolved problems. Plast Reconstr Surg 96:272-283, 1995

46. McCarthy JG, Glasberg SB, Cutting CB, et al: Twenty-year experience with early surgery for craniosynostosis: II. The craniofacial synostosis syndromes and pansynostosis--results and unsolved problems. Plast Reconstr Surg 96:284-295, 1995

47. McComb JG: Treatment of functional lambdoidal synostosis. Neurosurg Clin North Am 2:665-672, 1991

48. Meyers GA, Day D, Goldberg R, et al: FGFR2 exon IIIa and IIIc mutations in Crouzon, Jackson-Weiss, and Pfeiffer syndromes: evidence for missense changes, insertions, and a deletion due to alternative RNA splicing. Am J Hum Genet 58:491-498, 1996

49. Muakkassa KF, Hoffman HJ, Hinton DR, et al: Lambdoid synostosis. Part 2: Review of cases managed at The Hospital for Sick Children, 1972-1982. J Neurosurg 61:340-347, 1984

50. Neilson KM, Friesel RE: Constitutive activation of fibroblast growth factor receptor-2 by a point mutation associated with Crouzon Syndrome. J Biol Chem 270:26037-26040, 1995

51. Persing J, Babler W, Winn HR, et al: Age as a critical factor in the success of surgical correction of craniosynostosis. J Neurosurg 54:601-606, 1981

52. Persing JA, Delashaw JB, Jane JA, et al: Lambdoid synostosis: surgical considerations. Plast Reconstr Surg 81:852-860, 1988

53. Pilgram TK, Vannier MW, Marsh JL, et al: Binary nature and radiographic identifiability of 
craniosynostosis. Invest Radiol 29:890-896, 1994

54. Posnick JC: Unilateral coronal synostosis (anterior plagiocephaly): current clinical perspectives. Ann Plastic Surg 36:430-447, 1996

55. Posnick JC, Armstrong D, Bite U: Metopic and sagittal synostosis: intracranial volume measurements prior to and after cranio-orbital reshaping in childhood. Plast Reconstr Surg 96:299-309, 1995

56. Posnick JC, Lin KY, Jhawar BJ, et al: Crouzon syndrome: quantitative assessment of presenting deformity and surgical results based on CT scans. Plast Reconstr Surg 92:1027-1037, 1993

57. Reddy K, Hoffman H, Armstrong D: Delayed and progressive multiple suture craniosynostosis. Neurosurgery 26:442-448, 1990

58. Renier D, Sainte-Rose C, Marchac D, et al: Intracranial pressure in craniostenosis. J Neurosurg 57:370-377, 1982

59. Sawin PD, Muhonen MG, Menezes AH: Quantitative analysis of cerebrospinal fluid spaces in children with occipital plagiocephaly. J Neurosurg 85:428-434, 1996

60. Sen A, Dougal P, Padhy AK, et al: Technicium-99m-HMPAO SPECT cerebral blood flow study in children with craniosynostosis. J Nucl Med 36:394-398, 1995

61. Shillito J: A plea for early operation for craniosynostosis. Surg Neurol 37:182-188, 1992

62. Shillito JJ, Matson DD: Craniosynostosis: a review of 519 surgical patients. Pediatrics 41:829-853, 1968

63. Siddiqi SN, Posnick JC, Buncic R, et al: The detection and management of intracranial hypertension after initial suture release and decompression for craniofacial dysostosis syndromes. Neurosurgery 36:703-709, 1995

64. Silver RK, MacGregor SN, Muhlbach LH, et al: Congenital malformations subsequent to chorionic villus sampling: outcome analysis of 1048 consecutive procedures. Prenat Diagn 14:421-427, 1994

65. Thompson DN, Harkness W, Jones B, et al: Subdural intracranial pressure monitoring in craniosynostosis: its role in surgical management. Childs Nerv Syst 11:269-275, 1995

66. Thompson DN, Malcolm GP, Jones BM, et al: Intracranical pressure in single-suture craniosynostosis. Pediatr Neurosurg 22:235-240, 1995

67. Tuite GF, Chong WK, Evanson J, et al: The effectiveness of papilledema as an indicator of raised intracranial pressure in children with craniosynostosis. Neurosurgery 38:272-278, 1996

68. Tuite GF, Evanson J, Chong WK, et al: The beaten copper cranium: a correlation between intracranial pressure, cranial radiographs, and computed tomographic scans in children with craniosynostosis. Neurosurgery 39:691-699, 1996

69. Turk AE, McCarthy JG, Thorne CHM, et al: The "back to sleep campaign" and deformational plagiocephaly: is there cause for concern? J Craniofac Surg 7:12-18, 1996

70. VanderKolk CA, Beaty T: Etiopathogenesis of craniofacial anomalies. Clin Plast Surg 21:481-488, 
71. VanderKolk CA, Carson BS: Lambdoid synostosis. Clin Plast Surg 21:575-584, 1994

72. VanderKolk CA, Carson BS, Robertson BC, et al: The occipital bar and internal osteotomies in the treatment of lambdoidal synostosis. J Craniofac Surg 4:112-118, 1993

73. Van Effenterre R, Houtteville JP, Phillippon J, et al: Intra-cranial pressure measurement in craniosynostosis after the first year. Neurochirurgie 22:59-67, 1976

74. Walker ML: Pathogenesis of craniosynostosis. Pediatr Neurosurg 22:280, 1995 (Letter)

75. Wall SA, Goldin JH, Hockley AD, et al: Fronto-orbital re-operation in craniosynostosis. Br J Plast Surg 47:180-184, 1994

76. Whittle IR, Johnston IH, Besser M: Intracranial pressure changes in craniostenosis. Surg Neurol 21:367-372, 1984

Manuscript received January 10, 1997.

Accepted in final form January 17, 1997.

Address reprint requests to: Benjamin S. Carson, M.D., Division of Pediatric Neurological Surgery, Johns Hopkins Medical Institutions, 600 North Wolfe Street, Harvey 811, Baltimore, Maryland 21287-8811.email: mguarnie@welchlink.welch.jhu.edu

Click here to view commentary on this article. 